\title{
A national-scale characterization of organochlorine pesticides (OCPs) in intertidal sediment of China: Occurrence, fate and influential factors $^{\text {is }}$
}

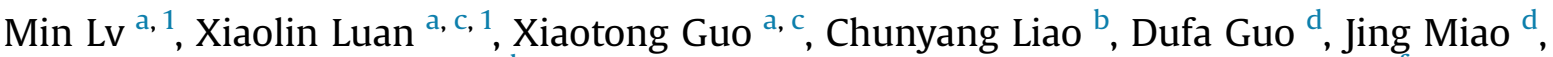 \\ Xiaqing $\mathrm{Wu}^{\mathrm{a}}{ }^{\mathrm{a}}$, Ruichen Zhou ${ }^{\mathrm{b}}$, Dongyan Liu ${ }^{\mathrm{a}}$, Dongqi Wang ${ }^{\mathrm{e}}$, Yanchuang Zhao ${ }^{\mathrm{f}}$, \\ Lingxin Chen ${ }^{\text {a, * }}$ \\ ${ }^{\text {a } C A S ~ K e y ~ L a b o r a t o r y ~ o f ~ C o a s t a l ~ E n v i r o n m e n t a l ~ P r o c e s s e s ~ a n d ~ E c o l o g i c a l ~ R e m e d i a t i o n, ~ Y a n t a i ~ I n s t i t u t e ~ o f ~ C o a s t a l ~ Z o n e ~ R e s e a r c h, ~ C h i n e s e ~ A c a d e m y ~ o f ~}$ \\ Sciences, Yantai, 264003, China \\ b State Key Laboratory of Environmental Chemistry and Ecotoxicology, Research Center for Eco-Environmental Sciences, Chinese Academy of Sciences, \\ Beijing, 100085, China \\ ${ }^{\mathrm{c}}$ University of Chinese Academy of Sciences, Beijing, 100049, China \\ ${ }^{\mathrm{d}}$ College of Geography and Environment, Shandong Normal University, Jinan, 250014, China \\ e School of Geographical Sciences, East China Normal University, Shanghai, 201100, China \\ ${ }^{\mathrm{f}}$ College of Information Science and Engineering, Henan University of Technology, Zhengzhou, 450001, China
}

\section{A R T I C L E I N F O}

\section{Article history:}

Received 9 July 2019

Received in revised form

13 November 2019

Accepted 13 November 2019

Available online 18 November 2019

\section{Keywords:}

Intertidal zone

Organochlorine pesticides (OCPs)

Sources

Risk assessment

Influential factors

\begin{abstract}
A B S T R A C T
Organochlorine pesticides (OCPs) have been restricted for application for about 30 years in China. Intertidal zone is a sink for anthropogenic pollutants, and to better understand the current pollution status of OCPs in China, 324 surface sediment samples collected from 14 typical intertidal zones of China were analyzed for 22 OCPs. The total concentrations of OCPs ranged from 0.051 to $4141.711 \mathrm{ng} / \mathrm{g}$, with DDTs and HCHs being the dominant components. Seasonal variations were not significant for most intertidal zones $(p>0.05)$, while significant spatial variations $(p<0.05)$ were found among 14 intertidal zones, with the highest OCPs concentrations detected in Jiulong Jiang (JLJ). The OCPs concentrations in intertidal sediments would rarely to frequently cause adverse biological effects and DDTs were the major threat. Apart from the historical usage of technical DDT and lindane, current usage of technical DDT and $\mathrm{HCH}$ were also implied, especially for intertidal zones such as Beidaihe (BDH) and Yingluo Wan (YLW). PCA analysis indicated that compounds within the same type of OCPs were from similar source, while different types of OCPs were generally from different sources and not used together. Our results further indicated that OCPs together with organic particles entered into the intertidal zones mainly through river input.
\end{abstract}

() 2019 Elsevier Ltd. All rights reserved.

\section{Introduction}

Organochlorine pesticides (OCPs), known for their features of degradation resistance, bioaccumulation, and biotoxicity (Jones and de Voogt, 1999; Tolosa et al., 1995), were extensively used in agriculture to increase the grain output and in public places to control malaria all over the world (Wong et al., 2005). Thirty years

\footnotetext{
This paper has been recommended for acceptance by Dr. Jörg Rinklebe.

* Corresponding author.

E-mail addresses: mlv@yic.ac.cn (M. Lv), lxchen@yic.ac.cn (L. Chen).

1 The first and the second authors equally contribute to this article.
}

have passed since the ban of technical dichlorodiphenyltrichloroethanes (DDTs) and hexachlorocyclohexanes (HCHs) (two representational OCPs) for agriculture application in China, but studies in recent 5 years revealed that their concentrations in atmosphere (Yu et al., 2019), water system (Wang et al., 2018), soil (Li et al., 2018; Yuan et al., 2017), biota (Zhou et al., 2014a), and sediment (Zhao et al., 2018) still remained at a high level. Various evidences indicate that there still exist fresh inputs of OCPs in China.

Through land reclamation, soil erosion, storm runoff, river input and deposition, chemical compounds together with particles finally enter the coastal environment where the sediment becomes the ultimate reservoir for contaminations (Huang et al., 2017; Li et al., 
2014). Intertidal zone, as a part of coastal zone, refers to the zone between the highest tidal level and the lowest tidal level of the spring tide period (Sun et al., 2018a). Healthy intertidal zone provides comfortable living conditions for benthic and epibenthic organisms (CCME, 1995). However, as the buffer zone of land and sea, intertidal zone has undergone a high frequency of human activities and suffered from the brunt of contaminations. Large amount of OCPs from land flew into the coastal environment and were deposited in the sediment (Lin et al., 2009). Published researches about OCPs contamination in intertidal sediments were mainly before 2010 at some densely-populated coastal regions in China (Chen et al., 2006; Lin et al., 2012; Lin et al., 2009; Qiu et al., 2005; Wang et al., 2007; Wu et al., 2016), and the information on current status of OCPs pollution in intertidal sediments were limited. Furthermore, there are still many coastal regions where OCPs pollution has rarely or not been investigated and a nation-scale investigation is thus needed.

In this project, 14 typical intertidal zones from north to south of China, spanning over 11 coastal provinces and municipalities of China, were selected as targeted research areas. Among the 14 intertidal zones, national nature reserves have been established at intertidal zones of Dongying (DY), Yancheng (YC), and Chang Jiang (CJ) to protect the migratory water birds and rare birds, and at intertidal zones of Yingluo Wan (YLW) and Dongzhai Gang (DZG) to protect the abundant mangrove resources (Fu et al., 2018; Li et al., 2019). And intertidal zones of Beidaihe (BDH) and Hangu (HG), Jiulong Jiang (JLJ), and Zhu Jiang (ZJ) locate near the famous BeijingTianjin-Hebei urban agglomeration district, Xiamen Economic Special Zone, and Pearl River Delta, respectively. What's more, it will be the first report on the occurrence of OCPs in intertidal zones including BDH, HG, Dagu He (DGH), YLW and DZG. This study aimed to present a nation-scale characterization of pollution status, risks, sources and fate of OCPs in China's intertidal sediments after about 30 years' restriction of typical OCPs and explore the key factors influencing OCPs distributions.

\section{Materials and methods}

\subsection{Sample collection and analysis}

14 typical intertidal zones along the $18,000 \mathrm{~km}$ continental coastline of China were chosen as the targeted area. The general geographical locations and names of the sampling sites were presented in Fig. 1, with more detailed information about sampling sites given in the Supplementary information (Table S1, SI). A total of 324 surface sediment samples were collected during dry season (Sept. 2014 to Feb. 2015) and wet season (Jul. to Sept. 2015). All individual samples were freeze-dried, ground with clean mortar, and stored at $-20{ }^{\circ} \mathrm{C}$ after sieving with 75 mesh sieve. Detailed information for analysis of sediment properties (total organic carbon (TOC), total nitrogen (TN) and total phosphorus (TP)) were given in the SI. For OCPs analysis, after extraction, cleaning up and concentration, samples were analyzed by gas chromatograph (Trace 1310, Thermo) equipped with triple quadrupole mass spectrometer (TSQ $8000 \mathrm{EVO}$, Thermo). 22 compounds belonging to five types of OCPs were targeted (Table 1), and they were identified and quantified in selective reaction mode (SRM), with two precursor ion/product ion transition pairs listed in Table S2. Detailed information for sample pretreatment and analysis for OCPs were provide in SI.

\subsection{Quality assurance and quality control $(Q A / Q C)$}

Strict QA/QC procedures were conducted. Each sample was spiked with recovery surrogates before extraction to indicate the

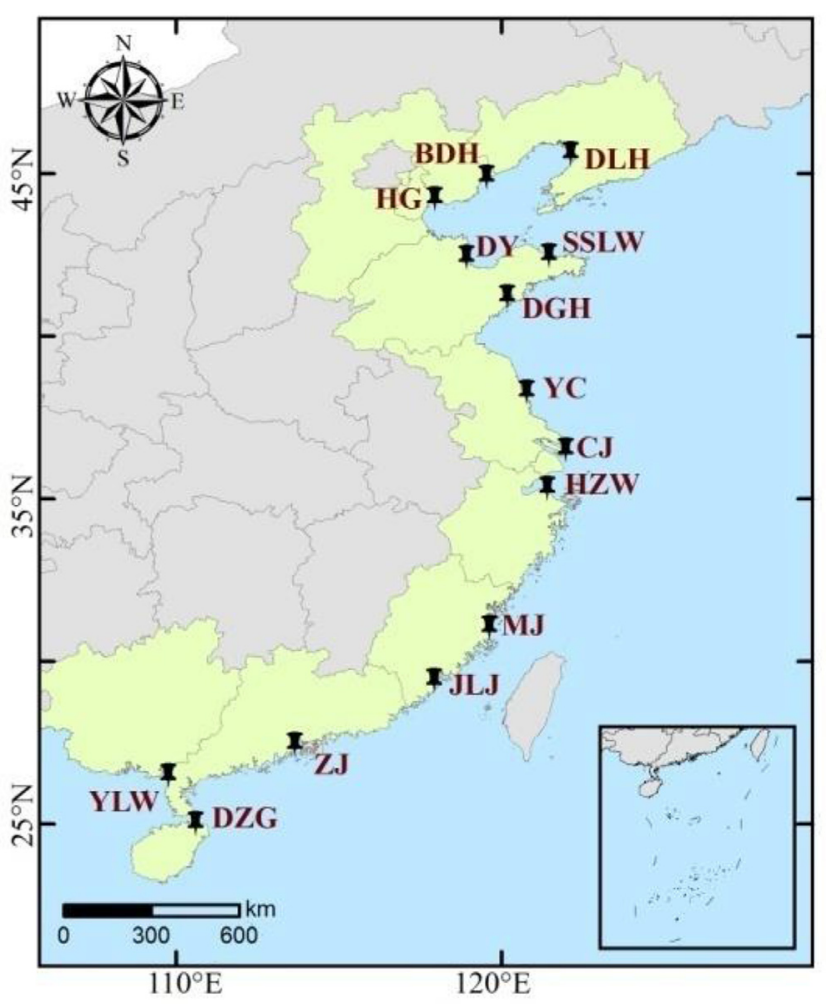

Fig. 1. Study area and geographical locations of 14 intertidal zones.

recoveries of target compounds. The recoveries of all targets ranged from $62 \%$ to $124 \%$. A procedural blank, a spiked blank, a matrix spike and a duplicate were run for each batch to monitor the whole process of analysis. OCPs in the procedural blanks were not detected, indicating no contamination of OCPs in the process. During the analysis by GC-MS/MS, a mixed OCPs standard was inserted about every ten practical samples to monitor the stability of the instrument. The deviation of quantitative results for standard solution was controlled within $20 \%$. S/N ratios $\geq 10$ were adopted to calculate the method detection limits (MDLs), and the MDLs for 22 target compounds were between 0.278 and $20.579 \mathrm{pg} / \mathrm{g}$ (Table 1).

\subsection{Statistical analysis}

All statistical analysis in this study were carried out with SPSS 16.0 for windows, and all figures were created by SigmaPlot 12.5 . Spearman correlation analysis was performed to analyze the correlation between 22 compounds. One-way ANOVA analysis was conducted to compare the concentrations of the targets. $P$-values less than 0.05 (two-tailed) were considered to be statistically significant. Principal component analysis (PCA) was performed to identify the sources of OCPs. Values under MDLs were set to zero during all calculation and statistical analysis process. All concentrations mentioned in this study were presented as ng/g dry weight $(\mathrm{dw})$.

\section{Results and discussion}

\subsection{Concentrations and distributions of OCPs in the sediments}

The total concentrations of 22 OCPs in 14 typical intertidal zones were exhibited in Fig. 2(a). It can be summarized that the OCPs concentrations among surface sediments of China's intertidal zones 
Table 1

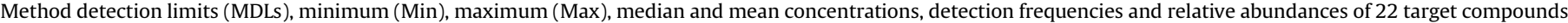
in surface sediments.

\begin{tabular}{|c|c|c|c|c|c|c|c|}
\hline \multirow{2}{*}{$\begin{array}{l}\text { Compound } \\
\text { name }\end{array}$} & \multirow{2}{*}{$\frac{\mathrm{MDL}}{\mathrm{pg} / \mathrm{g}}$} & Min & Max & Median & Mean & Detect & Relative abundance \\
\hline & & \multicolumn{4}{|c|}{$\mathrm{ng} / \mathrm{g}$} & \multicolumn{2}{|c|}{$\%$} \\
\hline$\alpha-\mathrm{HCH}$ & 0.364 & $<\mathrm{MDL}$ & 1.756 & 0.104 & 0.139 & 97.7 & $5.7 \pm 7.8$ \\
\hline$\beta-\mathrm{HCH}$ & 0.529 & $<\mathrm{MDL}$ & 1.846 & 0.097 & 0.137 & 98.1 & $3.9 \pm 3.3$ \\
\hline$\delta-\mathrm{HCH}$ & 0.739 & $<\mathrm{MDL}$ & 1.135 & 0.027 & 0.055 & 87.7 & $1.7 \pm 2.0$ \\
\hline$\gamma-\mathrm{HCH}$ & 0.574 & $<\mathrm{MDL}$ & 0.327 & 0.022 & 0.046 & 94.8 & $2.0 \pm 2.6$ \\
\hline$\sum \mathrm{HCHs}$ & & 0.005 & 5.064 & 0.249 & 0.378 & 99.0 & $12.9 \pm 11.8$ \\
\hline$p, p^{\prime}-\mathrm{DDD}$ & 0.335 & $<\mathrm{MDL}$ & 1611.322 & 0.332 & 6.810 & 98.1 & $17.2 \pm 11.5$ \\
\hline$o, p^{\prime}-\mathrm{DDD}$ & 0.361 & $<\mathrm{MDL}$ & 355.025 & 0.122 & 1.578 & 87.1 & $5.6 \pm 3.8$ \\
\hline$p, p^{\prime}-\mathrm{DDE}$ & 0.352 & $<\mathrm{MDL}$ & 363.997 & 0.314 & 2.249 & 90.6 & $15.0 \pm 10$ \\
\hline$o, p^{\prime}-\mathrm{DDE}$ & 0.278 & $<\mathrm{MDL}$ & 57.524 & 0.026 & 0.327 & 82.8 & $1.6 \pm 1.9$ \\
\hline$p, p^{\prime}-\mathrm{DDT}$ & 0.401 & $<\mathrm{MDL}$ & 1554.570 & 0.415 & 7.392 & 98.1 & $25.6 \pm 17.8$ \\
\hline$o, p^{\prime}-\mathrm{DDT}$ & 0.424 & $<\mathrm{MDL}$ & 235.550 & 0.139 & 1.253 & 95.1 & $6.7 \pm 4.5$ \\
\hline$\sum D D T s$ & & 0.033 & 4140.071 & 1.558 & 19.633 & 100.0 & $70.2 \pm 23.0$ \\
\hline$\alpha$-Chlordane & 2.345 & $<\mathrm{MDL}$ & 0.372 & $<\mathrm{MDL}$ & 0.019 & 50.5 & $0.8 \pm 1.9$ \\
\hline$\gamma$-Chlordane & 11.743 & $<\mathrm{MDL}$ & 0.789 & $<\mathrm{MDL}$ & 0.030 & 45.0 & $0.9 \pm 2.6$ \\
\hline Heptachlor & 0.790 & $<\mathrm{MDL}$ & 0.163 & $<\mathrm{MDL}$ & 0.024 & 35.0 & $1.0 \pm 2.3$ \\
\hline Heptachlor epoxide & 4.382 & $<\mathrm{MDL}$ & 0.216 & $<\mathrm{MDL}$ & 0.012 & 18.4 & $0.5 \pm 1.5$ \\
\hline$\sum \mathrm{CHLS}$ & & $<\mathrm{MDL}$ & 0.947 & 0.015 & 0.085 & 77.7 & $3.0 \pm 6.0$ \\
\hline Aldrin & 2.730 & $<\mathrm{MDL}$ & 0.149 & $<\mathrm{MDL}$ & 0.005 & 13.9 & $0.5 \pm 2.6$ \\
\hline Dieldrin & 5.737 & $<\mathrm{MDL}$ & 0.120 & $<\mathrm{MDL}$ & 0.003 & 6.5 & $0.3 \pm 2.0$ \\
\hline Endrin & 8.921 & $<\mathrm{MDL}$ & 0.785 & $<\mathrm{MDL}$ & 0.111 & 33.0 & $4.6 \pm 10.2$ \\
\hline Endrin Aldehyde & 12.869 & $<\mathrm{MDL}$ & 2.703 & $<\mathrm{MDL}$ & 0.032 & 12.9 & $1.3 \pm 5.3$ \\
\hline Endrin Ketone & 20.579 & $<\mathrm{MDL}$ & 0.174 & $<\mathrm{MDL}$ & 0.012 & 14.6 & $0.5 \pm 1.7$ \\
\hline$\sum$ Drins & & $<\mathrm{MDL}$ & 12.884 & $<\mathrm{MDL}$ & 0.167 & 45.1 & $6.6 \pm 12.7$ \\
\hline Endosulfan I & 2.556 & $<\mathrm{MDL}$ & 0.419 & $<\mathrm{MDL}$ & 0.023 & 41.4 & $1.0 \pm 2.1$ \\
\hline Endosulfan II & 3.894 & $<\mathrm{MDL}$ & 0.317 & $<\mathrm{MDL}$ & 0.027 & 25.9 & $1.0 \pm 3.2$ \\
\hline Endosulfan sulfate & 1.262 & $<\mathrm{MDL}$ & 0.929 & 0.019 & 0.056 & 87.1 & $2.6 \pm 5.0$ \\
\hline$\sum$ Ends & & $<\mathrm{MDL}$ & 3.212 & 0.034 & 0.116 & 89.0 & $4.4 \pm 7.2$ \\
\hline$\sum \mathrm{OCPs}$ & & 0.051 & 4141.711 & 2.114 & 20.378 & & \\
\hline
\end{tabular}

ranged from 0.051 to $4141.711 \mathrm{ng} / \mathrm{g}$, with a median value of $2.114 \mathrm{ng} / \mathrm{g}$ (Table 1). DDTs were the major contaminants (between 0.033 and $4140.071 \mathrm{ng} / \mathrm{g}$, with a median value of $1.558 \mathrm{ng} / \mathrm{g}$ ), followed by HCHs (between 0.005 and $5.064 \mathrm{ng} / \mathrm{g}$, with a median value of $0.249 \mathrm{ng} / \mathrm{g}$ ). In this study, the mean contributions of DDTs and $\mathrm{HCHs}$ to total OCPs concentrations were $70.2 \%$ and $12.9 \%$, and detection frequencies of DDTs and $\mathrm{HCHs}$ were $100.0 \%$ and $99.0 \%$, respectively. For CHLs, Drins, and Ends, their mean contributions to total OCPs concentrations were $3.0 \%, 6.6 \%$, and $4.4 \%$, and detection frequencies were $77.7 \%, 45.1 \%$, and $89.0 \%$, respectively.

Spatial variations were observed for total concentrations of OCPs and five specific types of OCPs (Fig. 2 and Table S3). The mean concentrations of total OCPs for 14 typical intertidal zones were as follows: JLJ (211.109 ng/g) > HG (11.190 ng/g) > DGH (9.675 ng/ g) $>$ ZJ $(7.550 \mathrm{ng} / \mathrm{g})>$ Min Jiang $(\mathrm{MJ}, 7.159 \mathrm{ng} / \mathrm{g})>\mathrm{CJ}(5.716 \mathrm{ng} /$ g) > Daliao He (DLH, $4.410 \mathrm{ng} / \mathrm{g})>$ DZG (4.149 ng/g) > Hangzhou Wan (HZW, $3.954 \mathrm{ng} / \mathrm{g})>$ Sishili Wan (SSLW, $3.377 \mathrm{ng} / \mathrm{g})>$ YLW $(3.120 \mathrm{ng} / \mathrm{g})>\mathrm{DY}(0.938 \mathrm{ng} / \mathrm{g})>\mathrm{YC}(0.932 \mathrm{ng} / \mathrm{g})>\mathrm{BDH}(0.655 \mathrm{ng} /$ $\mathrm{g})$. The total OCPs concentrations were highest in JLJ $(p<0.05)$, followed by HG and DGH with significantly higher total OCPs concentrations than DY, YC, and BDH $(p<0.05)$. No significant variations $(p>0.05)$ were found among other 8 intertidal zones. Since DDTs accounted for $48.0 \%-91.6 \%$ of the total concentrations of OCPs (Fig. S1), their spatial distribution pattern was almost the same as total OCPs. For HCHs, accounting for $5.7 \%-27.3 \%$ of the total OCPs concentrations, the mean concentrations were significant higher in south China $(p<0.05)$ with the top 5 intertidal zones following the order: JLJ $(1.372 \mathrm{ng} / \mathrm{g})>\mathrm{MJ}(0.651 \mathrm{ng} / \mathrm{g})>\mathrm{CJ}$ $(0.425 \mathrm{ng} / \mathrm{g})>\mathrm{HZW}(0.398 \mathrm{ng} / \mathrm{g})>\mathrm{ZJ}(0.392 \mathrm{ng} / \mathrm{g})$. These results agreed well with the fact that the technical $\mathrm{HCH}$ consumption in southeastern China was larger than other regions in China (ElShahawi et al., 2010; Huang et al., 2018). CHLs, Drins, and Ends were all detected at low concentrations and frequencies in this study, which were consistent with previous studies (Wang et al.,
2007; Zhang et al., 2011), and this may be due to their point sources instead of widespread usage, like pesticide factory and farmland (Fang et al., 2016; Zhang et al., 2011; Zhao et al., 2013). For CHLs and Drins, no significant spatial variations were observed $(p>0.05)$. While for Ends, their concentrations were higher in MJ compared with the other 13 intertidal zones $(p<0.05)$.

Compared with spatial variations, seasonal variations were less significant (Fig. 2 and Table S4). No significant variations in total OCPs concentrations and its major components HCHs and DDTs were observed between dry season and wet season for most intertidal zones $(p>0.05)$, while for CHLs and Drins, the seasonal variations were significant $(p<0.05)$ for several intertidal zones including DGH and JLJ, with higher concentrations in dry season than wet season. For HCHs, DDTs, Ends, and total OCPs concentrations, even though seasonal variations for most intertidal zones were not significant $(p>0.05)$, their mean concentrations were generally higher in dry season, indicating that high temperature and abundant rainfall in wet season could possibly lead to the reduction of contamination in sediments (Guo et al., 2009), while the less significance also indicated that high amount of OCPs could be transported into the intertidal zones from OCPs-polluted soil through surface runoff (Li et al., 2014). Hence, seasonal variation is an important factor that cannot be ignored, and complex factors might lead to different variations.

Due to their wide usage, HCHs and DDTs have been the mostly investigated OCPs worldwide (Table S5 and S6). In general, HCHs concentrations in this study were comparable or lower than those previously reported in sediments of estuaries and bays in China (Liu et al., 2013; Tan et al., 2009; Wu et al., 2016; Zhang et al., 2002; Zhou et al., 2014b), Alexandria Harbor of Egypt (Barakat et al., 2002), Bengal Bay of India (Rajendran et al., 2005), Ulsan Bay of Korea (Khim et al., 2001), Lots Sea of Spain (Mohammed et al., 2011), Guajará Bay of Brazil (Neves et al., 2018), Mediterranean Sea near Egypt (Nemr and Sadaawy, 2016), coast of Singapore (Wurl 

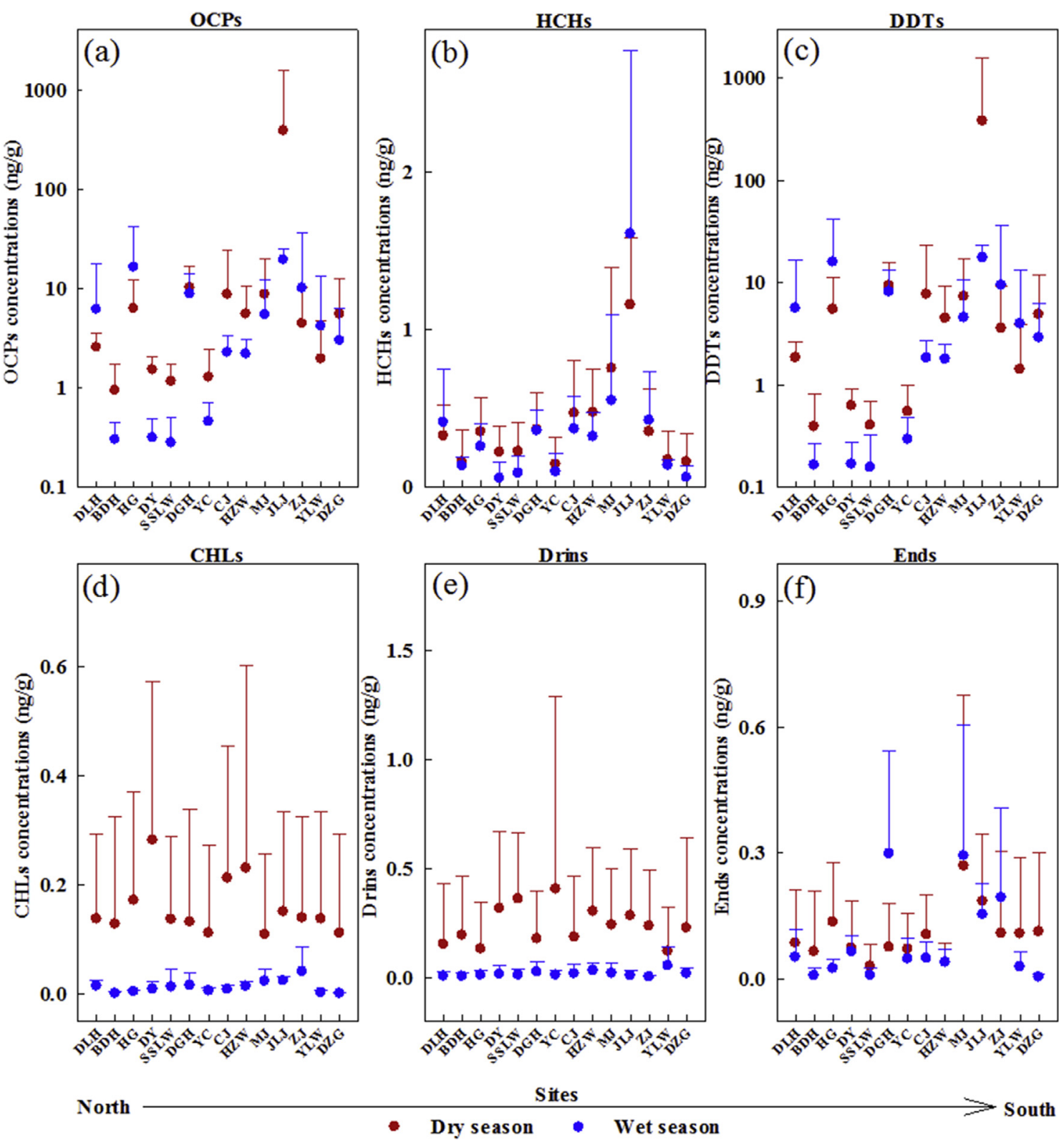

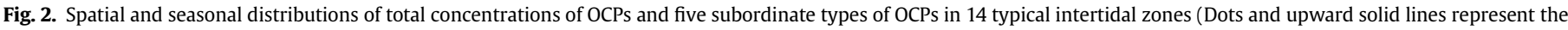
mean concentrations and the corresponding standard deviations).

and Obbard, 2005), Naples and Salerno Gulfs of Italy (Qu et al., 2018), while higher than Gulf of Aden (Mostafa et al., 2007) and Casco Bay of USA (Kennicutt et al., 1994). As for DDTs, one sample with extremely high DDTs concentration was detected in this study, which was 2-2000 times higher than those reported in previous studies (Table S5 and S6). Generally, DDTs concentrations in this study were comparable or higher than those reported in sediments of harbors, bays, and estuaries in Africa, Europe, North and South America, and Asia (Table S5 and S6).

To the best of our knowledge, this is the first report of OCPs occurrence in intertidal zones including BDH, HG, DGH, YLW and DZG. Special attention should be paid to HG and DGH, due to the existence of high OCPs concentrations, especially DDTs in these areas. Most previous studies in China focused on areas including $\mathrm{DLH}, \mathrm{CJ}, \mathrm{MJ}$, JLJ and ZJ, and most of these studies were conducted before 2010, which allowed us to evaluate the occurrence of $\mathrm{HCHs}$ and DDTs in the environment in a long time view after they were officially banned (Table S5). Interestingly, varied trends were observed for HCHs and DDTs. For HCHs, a general declining trend was found since 1990s, indicating that the ban of technical $\mathrm{HCH}$ after 1983 efficiently decreased the discharge of $\mathrm{HCHs}$ into the environment. In contrast, DDTs concentrations were comparable or even higher than those reported decades before. For example, DDTs concentrations in JLJ in this study were $10.868-4140.071 \mathrm{ng} / \mathrm{g}$, with a mean concentration of $209.228 \mathrm{ng} / \mathrm{g}$, which were higher than those reported in year 2009 (Wu et al., 2016) and 1999 (Yuan et al., 2001), indicating that new emissions of DDTs into the environment existed.

\subsection{Risk assessment of OCPs in intertidal sediments}

In order to evaluate the potential adverse biological effects of OCPs in intertidal sediments of China, sediment quality guidelines (SQGs) for the protection of aquatic life in marine environment 
(including estuary) proposed by the Canadian Council of Ministers of the Environment (CCME) and SQGs proposed by the US National Oceanic and Atmospheric Administration (NOAA) were both adopted in this study. According to CCME, interim sediment quality guideline (ISQG) and probable effect level (PEL) are set, and concentrations below ISQG, between ISQG and PEL and above PEL indicates adverse biological effects rarely (fewer than 25\%), occasionally (25\%-50\%) and frequently (more than 50\%) occurred, respectively. Accordingly, effect range-low (ERL) and effect rangemedian (ERM) in NOAA have similar meanings with ISQG and PEL, respectively.

According to CCME, $99.7 \%, 100.0 \%, 100.0 \%, 100.0 \%$, and $99.7 \%$ of the surface sediments had concentrations below the ISQGs for $\gamma$ $\mathrm{HCH}$, heptachlor epoxide, chlordane, dieldrin, and endrin, respectively, while only $76.6 \%, 88.0 \%, 67.5 \%$, and $70.1 \%$ of the surface sediments had concentrations below the ISQGs for $p, p^{\prime}$-DDD, $p, p^{\prime}$ DDE, $p, p^{\prime}$-DDT and total DDTs, respectively (Fig. 3, Table S7 and S8). Notably, $3.9 \%, 0.0 \%, 11.7 \%$, and $1.6 \%$ of the surface sediments had concentrations above the PELs for $p, p^{\prime}-\mathrm{DDD}, p, p^{\prime}$-DDE, $p, p^{\prime}$-DDT and total DDTs, respectively, indicating that DDTs were the main threat. According to NOAA, higher risks of DDTs were also indicated, with concentrations in $80.8 \%, 88.6 \%, 65.9 \%$, and $50.0 \%$ of the surface sediments below the ERLs for $p, p^{\prime}$-DDD, $p, p^{\prime}$-DDE, $p, p^{\prime}$-DDT and total DDTs, respectively, while concentrations in $1.0 \%, 0.6 \%, 8.1 \%$, and $1.6 \%$ of the surface sediments above the ERMs. Hence, with DDTs as the main threat, $11.4 \%-50.0 \%$ of intertidal sediments in this study would occasionally or frequently face adverse biological effects.

Considering that pesticides in the environment exist in mixture, sediment quality guideline quotient (SQGQ) was further adopted to evaluate the overall ecotoxicological risks for 14 typical intertidal zones using the above 8 pesticides with known PELs (Table S9). The lower the value of SQGQ is, the lighter the pollution is. Three levels of biological effects can be grouped according to the values of SQGQ: (1) no adverse biological effects (SQGQ < 0.1); (2) moderate adverse biological effects $(0.1 \leq \mathrm{SQGQ}<1)$; and (3) high adverse biological effects (SQGQ $\geq 1$ ) (Costa et al., 2011; MacDonald et al., 2004). For BDH, DY, and YC, where $100 \%$ of sediments samples had concentrations below the ISQGs (Fig. 3 and Table S8), their SQGQ values were all below 0.1 (Table S9). For DLH, SSLW, CJ, HZW, YLW and DZG, where more than $65 \%$ of sediment samples had concentrations below ISQGs and less than $25 \%$ of sediment samples had concentrations above the PELs (Fig. 3 and Table S8), more than $75 \%$ of their sediment samples had SQGQ values below 0.1 and no sediment samples had values above 1.0 (Table S9). For HG, DGH, MJ, and ZJ, where percentages of samples with concentrations below ISQGs were lower and above PELs were higher, the percentages of samples with SQGQ values below 0.1 and above 1.0 were $34 \%-88 \%$ and $0 \%-4 \%$, respectively. For JLJ, where less than $10 \%$ of sediment samples had concentrations below ISQGs, all samples had SQGQ values above 0.1 , with $9 \%$ above 1.0 .

The results using the above two methods for risk assessment were consistent, with OCPs concentrations in 9 intertidal zones including DLH, BDH, DY, SSLW, YC, CJ, HZW, YLW and DZG showing no or low risks, while the other 5 intertidal zones were faced with moderate to high risks from OCPs. Special attention should be paid to JLJ, where all samples showed moderate to high risks. Considering that DDTs concentrations in JLJ were higher in this study compared with previous reports, future and continuous investigation should be conducted in this area.

\subsection{Sources and fate analysis}

Technical DDT has been widely used in China between 1950s and 1980s (Wong et al., 2005), which has caused severe soil contamination and become the main sources of DDT and its metabolites in the environment through land reclamation and rainfall erosion (Lin et al., 2009; Liu et al., 2016). 250 tons of DDT have been used for yearly for producing antifouling paints to protect the body of boat from 1950s to 2005 in China (Yu et al., 2011) and antifouling paints were reported to be an important source of DDTs in fishing harbors of China (Zhou et al., 2014b). The usage of technical DDT in agriculture and as additives of antifouling paints was officially banned in 1983 and 2014, respectively in China, but it is still permitted for emergency vector control and dicofol production (Fujii et al., 2011). Dicofol, one of the organochlorine insecticides extensively used in modern agriculture and animal husbandry, is synthesized with DDT and contains high levels of DDT impurity (Qiu et al., 2005; Turgut et al., 2009). To date, there are mainly four sources of DDTs: historical technical DDTs contaminated soil, direct usage of technical DDT for disease transmission control, antifouling paints containing technical DDT, and dicofol.

Technical DDT generally consists of $15-20 \% \quad$, p'-DDT and 80-85\% p,p'-DDT (Metcalf, 1973), while dicofol contains higher o, $p^{\prime}-$ DDT content. Hence, DDTs sources can be speculated by the ratio of $o, p^{\prime}-\mathrm{DDT} / p, p^{\prime}-\mathrm{DDT}$, with ratios of $0.2-0.3$ and $4.8-9.2$ indicating the source of technical DDT and the source of dicofol, respectively (Liu et al., 2008b; Qiu et al., 2005). DDD and DDE are the major metabolites of DDT under the environment of anaerobic and aerobic, respectively. The ratio of (DDE+DDD)/DDT can be utilized to judge degradation degree of DDT, and the value 1.0 is regarded as the critical value, with high value indicating a long-term weathered DDT source, while low value indicating a current DDT input (Hong et al., 1999; Liu et al., 2015). Degradation environment for DDT can be judged by the ratio of DDD/DDE, with values above 1.0 and below 1.0 indicating an anaerobic dominant environment and an aerobic dominant environment, respectively. As shown in Fig. S2(a), the ratios of $o, p^{\prime}$-DDT/p,p'-DDT ranged from 0.0 to 0.9 , indicating that the contamination was mainly from technical DDT with rarely dicofol sources. This was consistent with a previous study that technical DDT contributed 95\% of the DDT source while dicofol contributed 5\% in 37 Chinese cities in 2005 (Liu et al., 2009). The ratios of (DDE+DDD)/DDT ranged from 0.0 to 21.4 with a median value of 1.1 (Fig. S2(b)), implying a multisource of history contamination and recent usage, and history contamination was the dominant source after taking into account DDT's slow degradation rate (Liu et al., 2015). (DDE+DDD)/DDT was further plotted with $o, p^{\prime}$-DDT/p,p'-DDT (Fig. S3(a)), and the ratios of $o, p^{\prime}-\mathrm{DDT} / p, p^{\prime}-$ DDT for samples with (DDE+DDD)/DDT lower than 1.0 ranged from 0.0 to 0.9 (with a median value of 0.2 ), further demonstrating that it was technical DDT rather than dicofol that contributed to recent DDT contamination in this study. The values of DDD/DDE ranged from 0.2 to 7.8 with a median value of 1.3 , indicating an anaerobic degradation dominant behavior of DDT for most intertidal zones (Fig. S2(c)), which likely implied oxygen depletion in these areas. However, a dominance of aerobic degradation other than anaerobic degradation was observed at CJ (Fig. S2(c)), which was inconsistent with previous reports (Liu et al., 2008a), implying a different environment of $\mathrm{CJ}$ intertidal zone from its adjacent estuaries and seas or a changed environment during the past years. To sum up, technical DDT mainly from historical usage was the main source of DDTs in China's intertidal zones. Also, recent usage of technical DDT either in antifouling paints or for disease transmission control also contributed to DDTs contamination, which was further verified by the above observation that DDTs concentrations in this study were comparable or even higher than those reported decades ago (Yuan et al., 2001). For surface sediments in most intertidal zones in China, anaerobic degradation is the dominant degradation mechanism of DDT.

Technical HCH, widely used during 1960s and 1970s, banned in 1983 and substituted by lindane from 1990s, was composed of $\alpha$ - 

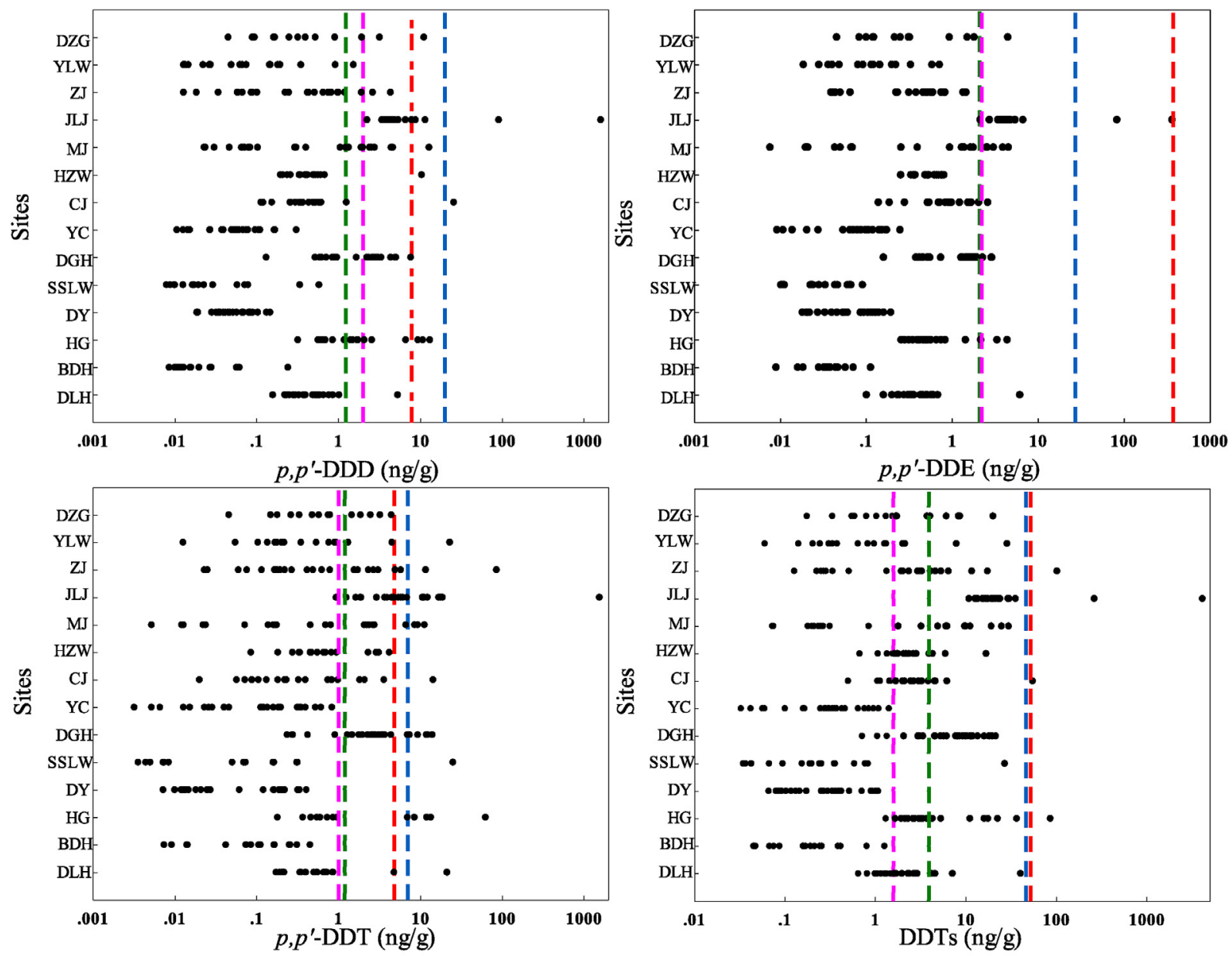

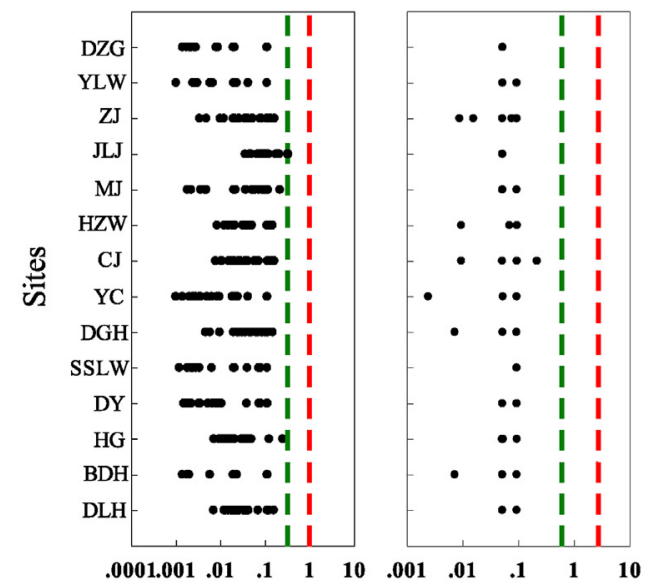

$\gamma$-HCH (ng/g) Heptachlor epoxide (ng/g)Chlordane (ng/g)

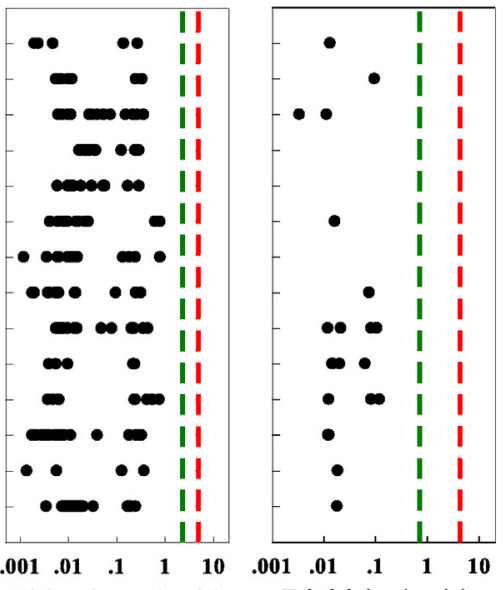

Dieldrin $(\mathrm{ng} / \mathrm{g})$

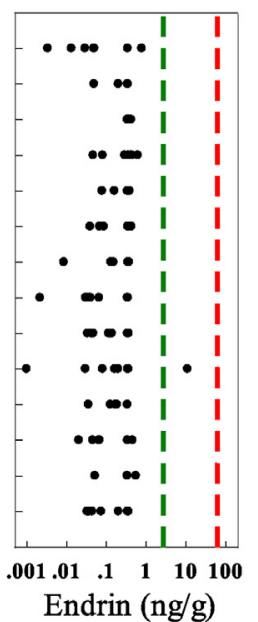

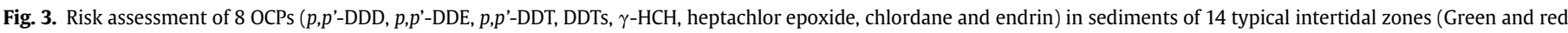

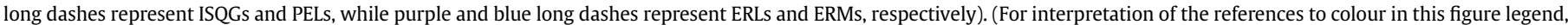
the reader is referred to the Web version of this article.)

$\mathrm{HCH}(65-70 \%), \beta-\mathrm{HCH}(5-6 \%), \gamma-\mathrm{HCH}(13 \%)$ and $\delta-\mathrm{HCH}(6 \%)$, whereas lindane was composed of $\gamma-\mathrm{HCH}$ (>99\%) (Li et al., 1998). $\mathrm{HCHs}$ contamination sources could thus be speculated by the ratio of $\alpha-\mathrm{HCH} / \gamma-\mathrm{HCH}$, with values of 3.0-7.0 indicating the source of technical $\mathrm{HCH}$ and values below 3.0 indicating the source of lindane (Li et al., 1998; Wang et al., 2018). $\beta-\mathrm{HCH}$ is the most antibiodegradation and stable isomer among all $\mathrm{HCH}$ isomers, and other isomers like $\gamma-\mathrm{HCH}$ and $\alpha-\mathrm{HCH}$ are relatively easy to be transformed into the more stable $\beta$-HCH isomer (Feng et al., 2011). Hence, the degradation degree of $\mathrm{HCHs}$ evaluated by $\beta-\mathrm{HCH} / \mathrm{HCH}$ could be used to discriminate the historical usage of $\mathrm{HCHs}$ and fresh input of HCHs (Li et al., 2018). In this study, the ratios of $\alpha-\mathrm{HCH} / \gamma$ $\mathrm{HCH}$ ranged from 0.0 to 6.0 (Fig. S2(d)), implying a multisource of technical $\mathrm{HCH}$ and lindane. Besides, the values of $\beta-\mathrm{HCH} / \mathrm{HCHs}$ ranged from 0 to 0.9 , with a median value of 0.4 (Fig. S2(e)), indicating that most $\mathrm{HCHs}$ were from historical usage. Notably, for BDH 
and YLW, their samples in wet season were clustered together and separated from other samples (Fig. S3(b)), and the ratios of $\alpha-\mathrm{HCH}$ were more than $65 \%$ in wet season, demonstrating that fresh input of technical $\mathrm{HCH}$ was the main source of $\mathrm{HCHs}$ for the two intertidal zones in wet season.

PCA was also performed in this study to further identify the OCPs sources. Six principal components with eigenvalues over 1 were extracted, with PC1, PC2, PC3, PC4, PC5, and PC6 accounting for $24.3 \%, 17.8 \%, 13.7 \%, 10.2 \%, 5.6 \%$ and $4.7 \%$ of the total variance, respectively (Table S10). Interestingly, regardless of PC4-PC6 which were associated with low frequently detected Drins, PC1-PC3 were correlated well with DDTs, HCHs, and CHLs and Ends, respectively, implying that the compounds within the same type of OCPs were from the same source, and CHLs and Ends were of similar source and probably used together. The results also indicated that CHLs and Ends have different sources with DDTs and HCHs. Consistent results were observed by correlation analysis for the 22 OCPs, with compounds within the same type significantly correlated with each other (Table S11). Since DDTs, HCHs, and CHLs and Ends were all mixtures of parent compounds and their metabolites (Da et al., 2014; Fang et al., 2016; Niu et al., 2017; Rahman et al., 2018; Sun et al., 2018b), the above results further verified that the main sources of them were of historical usage.

Further correlation analysis revealed that OCPs were generally significantly and positively correlated with sediment properties (TN, TP and TOC) and riverine based anthropogenic parameters, while significantly and negatively correlated with province based parameters (Table S12). The opposite correlations of OCPs concentrations with riverine based and province based pesticide consumptions indicated that OCPs in intertidal sediments were mainly from riverine input rather than local areas. Considering that pesticide consumption was clustered with population and GDP (Fig. 4), the relative variation in pesticide consumption could to some extent represent the situation in the past decades. Besides, since TOC was significantly and positively correlated with riverine based anthropogenic parameters (Table S13), the strong and positive correlations of OCPs with TOC, TN and TP further implied that through soil erosion, storm runoff and river input, OCPs

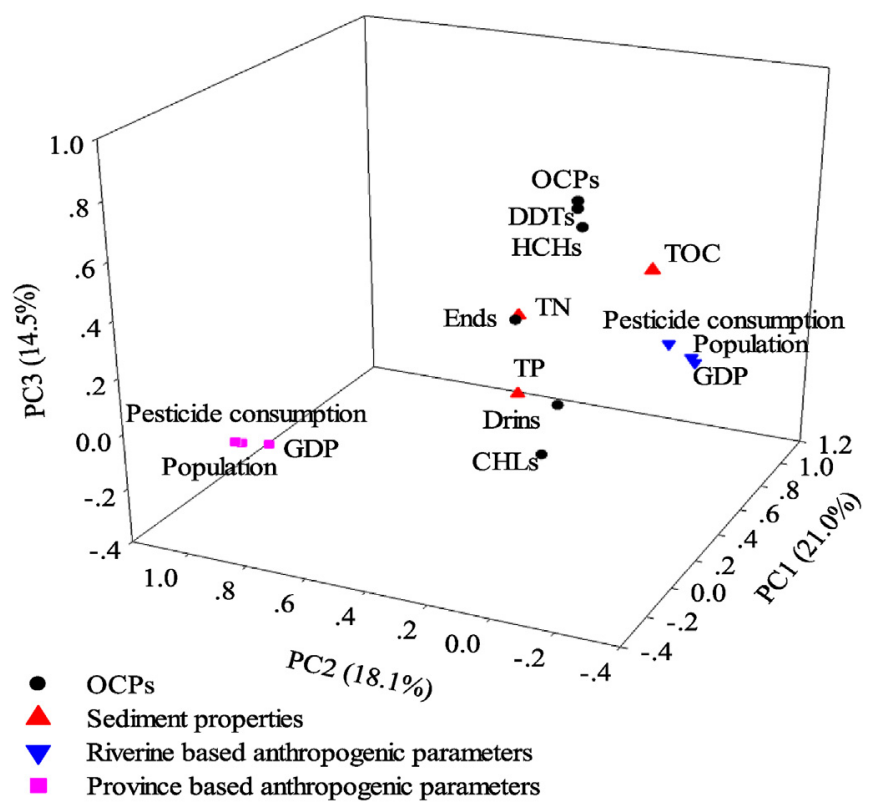

Fig. 4. PCA analysis of OCPs, sediment properties, riverine based and province based anthropogenic parameters. continuously entered into the intertidal zones together with organic particles.

\section{Conclusions}

This study will be the first systematic nation-scale investigation on the occurrence, distributions, fate and influential factors of OCPs in sediments of China's intertidal zones. The results showed that OCPs concentrations ranged from 0.051 to $4141.711 \mathrm{ng} / \mathrm{g}$ in intertidal sediments of China, indicating that OCPs still remained at a high level, especially for DDTs which accounted for around $70 \%$ of the total OCPs. By comparison with previous studies, HCHs concentrations in intertidal sediments presented a decreasing tendency, while DDTs showed no sign of decrease for most intertidal zones. Particularly, strikingly high levels of DDTs were observed in JLJ, where all samples showed moderate to high risks. The high concentrations of OCPs were not only attributed to their higher historical inputs, but also because of the existence of recent usage of technical DDT and technical HCH. Notably, an anaerobic dominant degradation was observed for DDT in most intertidal zones, and further studies are needed to investigate how much the dominant degradation pathway of DDT in the environment has been influenced by human activities. PCA analysis showed that compounds within the same type were significantly correlated $(p<0.05)$ and compounds from different types were separated from each other, indicating that compounds within the same type were likely from similar source. Further analysis implied that OCPs continuously entered into the intertidal zones through runoff and river input. Overall, the results indicated that further and continuous attention should be paid to OCPs pollution.

\section{Declaration of competing interest}

We declare no conflict of interest.

\section{CRediT authorship contribution statement}

Min Lv: Conceptualization, Investigation, Writing - review \& editing. Xiaolin Luan: Investigation, Writing - original draft. Xiaotong Guo: Investigation. Chunyang Liao: Resources, Project administration, Funding acquisition. Dufa Guo: Investigation. Jing Miao: Investigation. Xiaqing Wu: Investigation. Ruichen Zhou: Investigation. Dongyan Liu: Project administration. Dongqi Wang: Investigation. Yanchuang Zhao: Investigation. Lingxin Chen: Supervision, Funding acquisition.

\section{Acknowledgments}

This work was supported by the funding sources: NSFC (41601525; 21677167), NSF of Shandong province (ZR2016DB07), the Basic Special Program of Ministry of Science and Technology, China (2014FY210600), the Thousand Young Talents Program of China and Taishan Scholar Project Special Funding. We are also thankful to the Open Fund of the State Key Laboratory of Environmental Chemistry and Ecotoxicology (No. KF2017-11).

\section{Appendix A. Supplementary data}

Supplementary data to this article can be found online at https://doi.org/10.1016/j.envpol.2019.113634.

\section{References}

Barakat, A.O., Moonkoo, K., Yoarong, Q., Wade, T.L., 2002. Organochlorine pesticides and PCB residues in sediments of Alexandria Harbour, Egypt. Mar. Pollut. Bull. 
44, 1426-1434.

CCME, 1995. Protocol for the Derivation of Canadian Sediment Quality Guidelines for the Protection of Aquatic Life. CCME EPC-98E, Ottawa, ON.

Chen, S.J., Luo, X.J., Mai, B.X., Sheng, G.Y., Fu, J.M., Zeng, E.Y., 2006. Distribution and mass inventories of polycyclic aromatic hydrocarbons and organochlorine pesticides in sediments of the Pearl River Estuary and the northern South China Sea. Environ. Sci. Technol. 40, 709-714.

Costa, P.M., Neuparth, T.S., Caeiro, S., Lobo, J., Martins, M., Ferreira, A.M., Caetano, M., Vale, C., DelValls, T.A., Costa, M.H., 2011. Assessment of the genotoxic potential of contaminated estuarine sediments in fish peripheral blood: laboratory versus in situ studies. Environ. Res. 111, 25-36.

Da, C.N., Liu, G.J., Sun, R.Y., Yuan, Z.J., Tang, Q., Liu, H.Q., 2014. Sources and risk assessment of organochlorine pesticides in surface soils from the nature reserve of the Yellow River Delta, China. Soil Sci. Soc. Am. J. 78, 779-786.

El-Shahawi, M.S., Hamza, A., Bashammakh, A.S., Al-Saggaf, W.T., 2010. An overview on the accumulation, distribution, transformations, toxicity and analytical methods for the monitoring of persistent organic pollutants. Talanta 80 , 1587-1597.

Fang, Y., Nie, Z., Die, Q., Tian, Y., Liu, F., He, J., Huang, Q., 2016. Spatial distribution, transport dynamics, and health risks of endosulfan at a contaminated site. Environ. Pollut. 216, 538-547.

Feng, J., Zhai, M., Liu, Q., Sun, J., Guo, J., 2011. Residues of organochlorine pesticides (OCPs) in upper reach of the Huaihe River, East China. Ecotoxicol. Environ. Saf, 74, 2252-2259.

Fu, H., Wang, W., Ma, W., Wang, M., 2018. Differential in surface elevation change across mangrove forests in the intertidal zone. Estuar. Coast. Shelf Sci. 207, 203-208.

Fujii, Y., Haraguchi, K., Harada, K.H., Hitomi, T., Inoue, K., Itoh, Y., Watanabe, T., Takenaka, K., Uehara, S., Yang, H.R., Kim, M.Y., Moon, C.S., Kim, H.S., Wang, P., Liu, A., Hung, N.N., Koizumi, A., 2011. Detection of dicofol and related pesticides in human breast milk from China, Korea and Japan. Chemosphere 82, 25-31.

Guo, Y., Yu, H.Y., Zeng, E.Y., 2009. Occurrence, source diagnosis, and biological effect assessment of DDT and its metabolites in various environmental compartments of the Pearl River Delta, South China: a review. Environ. Pollut. 157, 1753-1763.

Hong, H.S., Chen, W.Q., Xu, L., Wang, X.H., Zhang, L.P., 1999. Distribution and fate of organochlorine pollutants in the Pearl River estuary. Mar. Pollut. Bull. 39, $376-382$.

Huang, H., Zhang, Y., Chen, W., Chen, W., Yuen, D.A., Ding, Y., Chen, Y., Mao, Y., Qi, S., 2018. Sources and transformation pathways for dichlorodiphenyltrichloroethane (DDT) and metabolites in soils from Northwest Fujian, China. Environ. Pollut. 235, 560-570.

Huang, Y., Zhang, R., Li, K., Cheng, Z., Zhong, G., Zhang, G., Li, J., 2017. Experimental study on the role of sedimentation and degradation processes on atmospheric deposition of persistent organic pollutants in a subtropical water column. Environ. Sci. Technol. 51, 4424-4433.

Jones, K.C., de Voogt, P., 1999. Persistent organic pollutants (POPs): state of the science. Environ. Pollut. 100, 209-221.

Kennicutt, M.C., Wade, T.L., Presley, B.J., Requejo, A.G., Brooks, J.M., Denoux, G.J., 1994. Sediment contaminants in Casco Bay, Maine: inventories, sources, and potential for biological impact. Environ. Sci. Technol. 28, 1-15.

Khim, S., Lee, K.T., Kannan, K., D L, 2001. Trace organic contaminants in sediment and water from Ulsan Bay and its vicinity, Korea. Arch. Environ. Contam. Toxicol. 40, 141-150.

Li, Q., Lu, Y., Wang, P., Wang, T., Zhang, Y., Suriyanarayanan, S., Liang, R., Baninla, Y., Khan, K., 2018. Distribution, source, and risk of organochlorine pesticides (OCPs) and polychlorinated biphenyls (PCBs) in urban and rural soils around the Yellow and Bohai Seas, China. Environ. Pollut. 239, 233-241.

Li, R., Zhang, L., Xue, B., Wang, Y., 2019. Abundance and characteristics of microplastics in the mangrove sediment of the semi-enclosed Maowei Sea of the south China sea: new implications for location, rhizosphere, and sediment compositions. Environ. Pollut. 244, 685-692.

Li, Y., Niu, J., Shen, Z., Zhang, C., Wang, Z., He, T., 2014. Spatial and seasonal distribution of organochlorine pesticides in the sediments of the Yangtze Estuary. Chemosphere 114, 233-240.

Li, Y.F., Cai, D.J., Singh, A., 1998. Technical hexachlorocyclohexane use trends in China and their impact on the environment. Arch. Environ. Contam. Toxicol. 35, 688-697.

Lin, T., Hu, L., Shi, X., Li, Y., Guo, Z., Zhang, G., 2012. Distribution and sources of organochlorine pesticides in sediments of the coastal East China Sea. Mar. Pollut. Bull. 64, 1549-1555.

Lin, T., Hu, Z., Zhang, G., Li, X., Xu, W., Tang, J., Li, J., 2009. Levels and mass burden of DDTs in sediments from fishing harbors: the importance of DDT-containing antifouling paint to the coastal environment of China. Environ. Sci. Technol. 43, 8033-8038.

Liu, L., Bai, L., Man, C., Liang, W., Li, F., Meng, X., 2015. DDT vertical migration and formation of accumulation layer in pesticide-producing sites. Environ. Sci. Technol. 49, 9084-9091.

Liu, L.Y., Ma, W.L., Jia, H.L., Zhang, Z.F., Song, W.W., Li, Y.F., 2016. Research on persistent organic pollutants in China on a national scale: 10 years after the enforcement of the Stockholm convention. Environ. Pollut. 217, 70-81.

Liu, M., Cheng, S., Ou, D., Yang, Y., Liu, H., Hou, L., Gao, L., Xu, S., 2008a. Organochlorine pesticides in surface sediments and suspended particulate matters from the Yangtze estuary, China. Environ. Pollut. 156, 168-173.

Liu, W., Chen, J., Hu, J., Ling, X., Tao, S., 2008b. Multi-residues of organic pollutants in surface sediments from littoral areas of the Yellow Sea, China. Mar. Pollut. Bull.
56, 1091-1103.

Liu, X., Zhang, G., Li, J., Yu, L.L., Xu, Y., Li, X.D., Kobara, Y., Jones, K.C., 2009. Seasonal patterns and current sources of DDTs, chlordanes, hexachlorobenzene, and endosulfan in the atmosphere of 37 Chinese cities. Environ. Sci. Technol. 43, 1316-1321.

Liu, Y.K., Zhong, G.C., Tang, J.H., Pan, X.H., Tian, C.G., Chen, Y.J., 2013. Concentrations and distribution of organochlorine pesticides in the surface sediments of Jiaozhou bay, Taozi bay and Sishili bay. Huanjing Kexue 34, 129-136.

MacDonald, D.D., Carr, R.S., Eckenrod, D., Greening, H., Grabe, S., Ingersoll, C.G., Janicki, S., Janicki, T., Lindskoog, R.A., Long, E.R., Pribble, R., Sloane, G., Smorong, D.E., 2004. Development, evaluation, and application of sediment quality targets for assessing and managing contaminated sediments in Tampa Bay, Florida. Arch. Environ. Contam. Toxicol. 46, 147-161.

Metcalf, R.L., 1973. Century of DDT. J. Agric. Food Chem. 21, 511-519.

Mohammed, A., Peterman, P., Echols, K., Feltz, K., Tegerdine, G., Manoo, A., Maraj, D., Agard, J., Orazio, C., 2011. Polychlorinated biphenyls (PCBs) and organochlorine pesticides (OCPs) in harbor sediments from Sea Lots, Port-of-Spain, Trinidad and Tobago. Mar. Pollut. Bull. 62, 1324-1332.

Mostafa, A.R., Wade, T.L., Sweet, S.T., Al-Alimi, A.K.A., Barakat, A.O., 2007. Assessment of persistent organochlorine residues in sediments of Hadramout coastal area, Gulf of Aden, Yemen. Mar. Pollut. Bull. 54, 1053-1058.

Nemr, A., Sadaawy, M.M., 2016. Polychlorinated biphenyl and organochlorine pesticide residues in surface sediments from the Mediterranean Sea (Egypt). Int. J. Sediment Res. 31, 44-52.

Neves, P.A., Colabuono, F.I., Ferreira, P.A.L., Kawakami, S.K., Taniguchi, S., Figueira, R.C.L., Mahiques, M.M., Montone, R.C., Bicego, M.C., 2018. Depositional history of polychlorinated biphenyls (PCBs), organochlorine pesticides (OCPs) and polycyclic aromatic hydrocarbons (PAHs) in an Amazon estuary during the last century. Sci. Total Environ. 615, 1262-1270.

Niu, L., Xu, C., Zhang, C., Zhou, Y., Zhu, S., Liu, W., 2017. Spatial distributions and enantiomeric signatures of DDT and its metabolites in tree bark from agricultural regions across China. Environ. Pollut. 229, 111-118.

Qiu, X.H., Zhu, T., Yao, B., Hu, J.X., Hu, S.W., 2005. Contribution of dicofol to the current DDT pollution in China. Environ. Sci. Technol. 39, 4385-4390.

Qu, C., Sun, Y., Albanese, S., Lima, A., Sun, W., Di Bonito, M., Qi, S.H., De Vivo, B., 2018. Organochlorine pesticides in sediments from Gulfs of Naples and Salerno, southern Italy. J. Geochem. Explor. 195, 87-96.

Rahman, M.M., Lee, H.S., Abd El-Aty, A.M., Kabir, M.H., Chung, H.S., Park, J.H., Kim, M.R., Kim, J.H., Shin, H.C., Shin, S.S., Shim, J.H., 2018. Determination of endrin and delta-keto endrin in five food products of animal origin using GCmuECD: a modified QuEChERS approach to traditional detection. Food Chem. 263, 59-66.

Rajendran, R.B., Imagawa, T., Tao, H., Ramesh, R., 2005. Distribution of PCBs, HCHs and DDTs, and their ecotoxicological implications in Bay of Bengal, India. Environ. Int. 31, 503-512.

Sun, W., Sun, Z., Mou, X., Sun, W., 2018a. Short-term study on variations of carbon dioxide and methane emissions from intertidal zone of the Yellow River Estuary during autumn and winter. Wetlands 38, 835-854.

Sun, Y., Yuan, G.L., Li, J., Tang, J., Wang, G.H., 2018b. High-resolution sedimentary records of some organochlorine pesticides in Yamzho Yumco Lake of the Tibetan Plateau: concentration and composition. Sci. Total Environ. 615, 469-475.

Tan, L., He, M.C., Men, B., Lin, C.Y., 2009. Distribution and sources of organochlorine pesticides in water and sediments from Daliao river estuary of Liaodong bay, Bohai sea (China). Estuar. Coast. Shelf Sci. 84, 119-127.

Tolosa, I., Bayona, J.M., Albaiges, J., 1995. Spatial and temporal distribution, fluxes, and budgets of organochlorinated compounds in Northwest Mediterranean sediments. Environ. Sci. Technol. 29, 2519-2527.

Turgut, C., Gokbulut, C., Cutright, T.J., 2009. Contents and sources of DDT impurities in dicofol formulations in Turkey. Environ. Sci. Pollut. Res. 16, 214-217.

Wang, H., He, M., Lin, C., Quan, X., Guo, W., Yang, Z., 2007. Monitoring and assessment of persistent organochlorine residues in sediments from the Daliaohe River watershed, northeast of China. Environ. Monit. Assess. 133, 231-242.

Wang, Y., Zhang, S., Cui, W., Meng, X., Tang, X., 2018. Polycyclic aromatic hydrocarbons and organochlorine pesticides in surface water from the Yongding River basin, China: seasonal distribution, source apportionment, and potential risk assessment. Sci. Total Environ. 618, 419-429.

Wong, M.H., Leung, A.O.W., Chan, J.K.Y., Choi, M.P.K., 2005. A review on the usage of POP pesticides in China, with emphasis on DDT loadings in human milk. Chemosphere 60, 740-752.

Wu, Y., Wang, X., Ya, M., Li, Y., Hong, H., 2016. Distributions of organochlorine compounds in sediments from Jiulong river estuary and adjacent Western Taiwan strait: implications of transport, sources and inventories. Environ. Pollut. 219, 519-527.

Wurl, O., Obbard, J.P., 2005. Organochlorine pesticides, polychlorinated biphenyls and polybrominated diphenyl ethers in Singapore's coastal marine sediments. Chemosphere 58, 925-933.

Yu, H.Y., Shen, R.L., Liang, Y., Cheng, H., Zeng, E.Y., 2011. Inputs of antifouling paintderived dichlorodiphenyltrichloroethanes (DDTs) to a typical mariculture zone (South China): potential impact on aquafarming environment. Environ. Pollut. 159, 3700-3705.

Yu, S.Y., Liu, W.J., Xu, Y.S., Zhao, Y.Z., Cai, C.Y., Liu, Y., Wang, X., Xiong, G.N., Tao, S., Liu, W.X., 2019. Organochlorine pesticides in ambient air from the littoral cities of northern China: spatial distribution, seasonal variation, source apportionment and cancer risk assessment. Sci. Total Environ. 652, 163-176.

Yuan, D.X., Yang, D.N., Wade, T.L., Qian, Y.R., 2001. Status of persistent organic 
pollutants in the sediment from several estuaries in China. Environ. Pollut. 114, $101-111$.

Yuan, H., Liu, E., Zhang, E., Luo, W., Chen, L., Wang, C., Lin, Q., 2017. Historical records and sources of polycyclic aromatic hydrocarbons (PAHs) and organochlorine pesticides (OCPs) in sediment from a representative plateau lake, China. Chemosphere 173, 78-88.

Zhang, G., Parker, A., House, A., Mai, B., Li, X., Kang, Y., Wang, Z., 2002. Sedimentary records of DDT and $\mathrm{HCH}$ in the Pearl River delta, south China. Environ. Sci. Technol. 36, 3671-3677.

Zhang, J., Qi, S., Xing, X., Tan, L., Gong, X., Zhang, Y., Zhang, J., 2011. Organochlorine pesticides (OCPs) in soils and sediments, southeast China: a case study in Xinghua Bay. Mar. Pollut. Bull. 62, 1270-1275.
Zhao, C., Xie, H., Zhang, J., Xu, J., Liang, S., 2013. Spatial distribution of organochlorine pesticides (OCPs) and effect of soil characters: a case study of a pesticide producing factory. Chemosphere 90, 2381-2387.

Zhao, Z., Jia, J., Wang, J., Liu, A., Lan, J., Zhang, H., Zhao, M., 2018. Pollution levels of DDTs and their spatiotemporal trend from sediment records in the Southern Yellow Sea, China. Mar. Pollut. Bull. 127, 359-364.

Zhou, S., Tang, Q., Jin, M., Liu, W., Niu, L., Ye, H., 2014a. Residues and chiral signatures of organochlorine pesticides in mollusks from the coastal regions of the Yangtze River Delta: source and health risk implication. Chemosphere 114, 40-50.

Zhou, S., Yang, H., Zhang, A., Li, Y.F., Liu, W., 2014b. Distribution of organochlorine pesticides in sediments from Yangtze River Estuary and the adjacent East China Sea: implication of transport, sources and trends. Chemosphere 114, 26-34. 